\title{
CORRIGENDUM: Fetal and adult human oligodendrocyte progenitor cells effectively myelinate dysmyelinated brain
}

Martha Windrem, Marta Nunes, William K Rashbaum, Theodore Schwartz, Robert A Goodman, Guy McKhann II, Neeta S Roy \&

Steven A Goldman

Nat. Med. 10, 93-97 (2004)

The panels in Figure $4 \mathrm{a}$ and $\mathrm{b}$ should be switched. The panel in Figure 4b should have been labeled 'a', and vice-versa.

CORRIGENDUM: Regulation of the innate and adaptive immune responses by Stat-3 signaling in tumor cells

Tianhong Wang, Guilian Niu, Marcin Kortylewski, Lyudmila Burdelya, Kenneth Shain, Shumin Zhang, Raka Bhattacharya, Dmitry Gabrilovich, Richard Heller, Domenico Coppola, William Dalton, Richard Jove, Drew Pardoll \& Hua Yu Nat. Med. 10, 48-54 (2004)

In Figure $3 \mathrm{c}$, the $x$-axis label for the second bar from the left was incorrect. The label should read, "Stat-3 $\beta$." In Figure $4 \mathrm{e}$ (top), the $y$-axis label was incorrect. The label should read, "IFN- $\gamma^{+}$(dots $/ 5 \times 10^{5}$ cells)." 